\title{
ONLINE RESOURCES FOR LANGUAGE REFERENCES AND CONSULTATIONS 1
}

\author{
Tatyana Aleksandrova \\ t_alexandrova_@mail.bg
}

Institute for Bulgarian Language, Bulgarian Academy of Sciences, Bulgaria

\begin{abstract}
The article presents the Guide "Internet language References" - a modern form for professional language counselling, through which the widest range of users can get a competent answer to their language questions. Guide has been developed by The Language consultation service in Institute for Bulgarian Language - BAS, and includes real user questions and answers related to the spelling, grammar and punctuation rules, with the meaning, use, origin and stylistic characteristics of the words, as well as the proper drafting of different types of texts. The usefulness of this electronic resource is highlighted. This resource provides researchers with reliable feedback on problematic points in the application of the rules of the literary language, which supports research and applied activity in the field of language culture. Questions and answers relating to spelling and speech norms are presented in more detail.
\end{abstract}

Keywords: Language Culture; Language Counselling; Online Guide; Spelling; Speech

\section{ОНААЙН РЕСУРСИ ЗА ЕЗИКОВИ СПРАВКИ И КОНСУАТАЦИИ²}

\section{Татяна АлексанАрова}

\author{
Институт за български език „Профо. Аюбомир АнАрейчин“, \\ Българска акалемия на науките
}

\begin{abstract}
Резюме: В статията се представя справочникът „Езикови справки по интернет" - съвременна орорма за профресионално езиково консултиране, чрез която максимално широк кръг от потребители могат да получат компетентен отговор на своите езикови въпроси. Справочникът е разработен от Службата за езикови справки и консултации към Института за български език и вк^ючва реални потребителски въпроси и отговори, свързани с
\end{abstract}

1 The article was prepared in implementation of the National Science Program "Cultural and Historical Heritage, National Memory and Social Development", funded by the Ministry of Education and Science

2 Статията е подготвена в изпьлнение на Националната научна програма "Културноисторическо наследство, национална памет и обществено развитие“, фоннансирана от МOH. 
правописните, правоговорните, граматичните и пунктуационните правила, със значението, употребата, произхола и стилистичната характеристика на Аумите, както и с правилното офрормяне на различни виАове текстове. Изтьква се полезността на този електронен ресурс, който предоставя на изследователите належАна обратна връзка за проблемните пунктове при прилагането на правилата на книжовния език, което подпомага научноизслеАователската и научнопри^ожната Аейност в областта на езиковата култура. По-подробно се представят въпросите и отговорите, отнасящи се Ао правописни и правоговорни норми.

КАючови Ауми: езикова култура; езиково консултиране;

онлайн справочник; правопис; правоговор

Езиковото консултиране е важен аспект от теорията и практиката на езиковата култура, разбирана в духа на Пражката Аингвистична школа като целенасочена теоретична обработка на книжовния език, като Аейност за неговото усъвършенстване и развитие с цел успешното изпьлнение на специалните му функции в обществото (Daneš, 1979). Екип езиковеАи от Института за български език при БАН, специалисти по книжовен език, на които е поверена и неговата кодификация чрез официалните правописни речници, извършват тази високоспециализирана и отговорна научноприложна Аейност с голяма обществена значимост.

През 2017 г. беше създален справочникът „Езикови справки по интернет" [Linguistic references - http://ibl.bas.bg/ezikovispravki/kategorii, (Last view: 20.09.2019)] - съвременна орорма за профресионално езиково консултиране, която отговаря на нужАата от належАна, компетентна и научно обоснована информация по езикови въпроси, предоставена чрез интернет. Той представлява оперативен онлайн ресурс и база данни на Службата за езикови справки и консултации, разработен съвместно с Аиректора на Института продр. Светла Коева и предназначен за максимално широк крьг от потребители. Справочникът съАьржа реални потребителски въпроси и техните отговори, обновява се ежедневно и е удобен и ^есен за използване, а в случай че потребителят не намери отговор на своя езиков въпрос, може

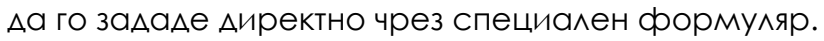


Службата, която е с повече от 60-годишна Аейност и е утвьрАена като национален експертен центьр, предоставя консултации по три канала: по теледрона, чрез електронната поща, а сега и чрез интернет справочника. По-голямата част от получените вьпроси се включват в справочника и по този начин се обогатява неговата база Аанни, с което Институтьт отговаря на съвременните потребности на обществото от бърза и компетентна помощ по езикови вьпроси, неограничена във времето и пространството. Справочникьт Аава възможност $а$ а се извьршва навременна нормативна оценка, т.е. $а$ а се $а$ але отговор на вьпроса кое е прави^но и кое - не, на непрекьснато появяващите се в езика нови явления. Чрез справочника целенасочено се работи за полобряване на езиковата култура на обществото, което Аопринася за полАьржане стабилността на книжовния език. Това е особено важно с оглеА на укрепване на неговия статут като Аьржавен език в Република България и като елин от най-важните елементи на националната ни иАентичност.

Систематизираната инфрормация, която сьдьржа непрекьснато обогатяващият се справочник „Езикови справки по интернет“, ще полпомогне идентифицирането на проблемните пунктове на колификацията и вземането на алекватни решения за нейното осьвременяване или оптимизиране. Тази инорормация ще бъле анализирана и използвана при следващите издания на Оорициалния правописен речник (Spelling dictionary, 2012) както при осъвременяването на неговия словник, така и при формулирането на прави^ата. В перспектива, много важен резултат от работата ще бъле оптимизирането на училищното образование по български език, тъй като справочникьт може да се използва и в обучението по правопис, пунктуация, граматика, мексикология. Това от своя страна ще Аопринесе за стабилизиране на книжовните норми.

Но постьпващите вьпроси са много повече от отражение на езиковите проблеми на обществото - в тях са колирани редица когнитивни аспекти. Езикьт е тясно свьрзан с познавателните процеси и с концептуализацията на света, която съдьржа както универсални, така и националноспециорични компоненти. 


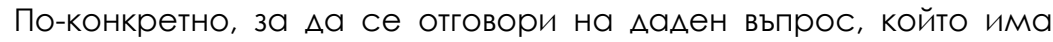
изхол в езиковите правила, често са необхолими и знания за извънезиковата действителност, които потребителите получават чрез обясненията на езиковедите. Такива са част от въпросите за главна и малка буква, слято, полуслято и разлелно писане, фрорми за число на Аумите, за оорормяне на абревиатури, част от въпросите за пунктуация. В този смисьл справочникът сьлейства за обогатяването на знанието в различни области и по този начин спомага за мичностното и общественото развитие.

При попьлването на справочника се спазват строги процедури, които гарантират Аостоверността и коректността на $А$ аваната информация, нейната системност и съответствие с кодиффицираните норми на книжовния език. Освен отговор по същество, към всеки въпрос има и кратко обяснение на правилото, като за целта се използва само базова мингвистична терминология, и насочване към речник, къАето може $\Delta$ а се открие правилото или инорормация за съответната Аума. Отговорите, веднъж въведени, се поллагат на научна редакция, която вкАючва и проверка Аали въпросът е правилно кАасифициран, и еАва слеА това се публикуват. Ао края на м. май 2019 г. в справочника са въведени 1250 въпроса и техните отговори. 750 от тях са публикувани и Аостьпни за потребителите. При по-сложните казуси, за които не може $\Delta a$ се намери елнозначно решение в действащите правила, се извършва проучване, резултатите от което се обсъжАат в екипа и еАва слел това се взема решение.

Структурата на справочника се отличава с гъвкавост и отворен характер; обхванати са всички езикови равнища, което отговаря на ^огиката на тралиционното мингвистично описание, както и на познавателното равнище на потребителите, формирано в процеса на обучение в средното образование. Същевременно са отчетени и особеностите на потребителските запитвания. Предварително, въз основа на Аостатьчно представителна извалка от въпроси, беше изработена специална класиоикация, която комбинира тралиционното деление по езикови категории със спецификата на 
отправените въпроси и отчита затрудненията при употребата на езиковите среАства.

Чрез нея всеки вьпрос се сьотнася с рубрика от съответната тематична област, като всяка рубрика е йерархично структурирана. Въпросите са класифицирани в няколко големи раздела, вътре в които е направена детайлна полкатегоризация. Така се постига по-улобно търсене от страна на потребителите, както и системно представяне на инорормацията с оглеА на бъдещите теоретични проучвания и на практическата колификация, извьршвана от езиковедите.

Класифрикацията, от енна страна, е полезна за потребителите, които чрез полето за тьрсене освен по дума и^и словосъчетание могат Аа търсят и по тематична рубрика, като по този начин имат възможност $\Delta$ a се запознаят С всички въпроси и отговори от еАна тематична об^аст и така $\Delta$ а обогатят своята езикова култура. Полезна е и за езиковеАите, тъй като им Аава Аобри възможности Аа изслеАват различни проблеми на съвременната употреба на езика, което е и енна от целите на справочника „Езикови справки по интернет“. Той е изкАючитеАно ценен като обратна връзка и източник на инорормация за реалните, а не предполагаемите от езиковедите трудности, които изпитват носителите на книжовния език при при^агането на прави^ата, за промените в нормите, за обществените нагласи, тъй като покрай конкретните си въпроси често потребителите споделят отношението си както към книжовния език като цяло, така и към отАеАни норми и тяхната колификация. Особено важно е това, че е налице активност в тьрсенето на езикова консултация от страна на Ава типа потребители: хора, които продресионално се занимават със съзАаване и обработка на различни типове текстове - автори, журналисти, редактори, коректори, преполаватели, пиари, автори на рекламно сьльржание, офрис сътрудници, служители в алминистрацията на различни равнища. Това са мотивирани хора, редовни потребители на езиковите консултации, за които Аоброто влалеене на книжовните норми е част от профресионалните им умения. Те съставляват ялрото на социалната база на книжовния език. Аругата група представ^яват хора, които по 
някакъв повол са се сбльскали с езиков проблем и използват услугата по-скоро спораАично.

Специалистите имат възможност Аа анализират в съпоставителен план езиковите затруднения в Авете основни групи потребители, $А$ а очертаят техния социално-езиков профри^ и Аа правят алекватни изволи за социалните аспекти на Аействието на коАиорикацията.

По-нататьк ще разгледаме по-полробно постьпилите въпроси от тематичната област "Правопис и правоговор", както и някои Аруги правописни въпроси с висока честота: слято, полуслято и разАелно писане, употреба на главни и малки букви и употреба на пьлен и кратьк ч^ен.

Всички правописни проблеми, свързани с релацията звук буква, са обхванати от класификацията: правопис на гласни: о или у (репертоар, умьрлушен), а или в (обрьщение и обращение - с различно значение; съоръжение; изговор на членувани съществителни от женски рол с ударение върху членната морорема от типа на кръвта), е или и (Ауминесцентен), променливо я (стяга, но стеги, разкрещял се, но разкрещели се; изговор и правопис на групи -ьр-, -ьл-; -рь-, -ль(Авугръб, но Авугрба, издържам, но издръжлив); на групи -еа-, -иа-; -ея, ия- при словообразуване и орормообразуване; правопис на съгласни звучни и беззвучни (Аогадка, Ажафокам), вмькване и изпускане на съгАасни (връстник, възпирам, наморАник, кеймбриАжки, шестстотин и др.); удвояване на съгласни (оттенък, подьържам, предлверие, странноприемница, именик и именник - в зависимост от значението).

УАвояването на преАлозите в/във и с/със, макар че е добре регламентирано от колифрикацията, също предизвиква затруднения в някои по-особени случаи: пред абревиатури на ^атиница, напр. с SMS,

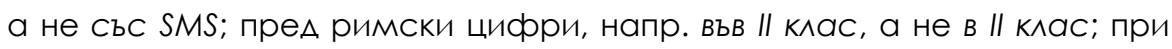
въвежлане на рубрики, когато текстьт преди пьрвата рубрика завьршва С предлог в или С. Аруга тематична област, в която има залалени значимо количество въпроси, е "Правопис на отАеАни Ауми и орорми“. Тук попалат Аве групи Ауми и орорми. ЕАната вКАючва преАимно Ауми от чужА произхол, по-отАавна или по-скоро заети в българския: алективен, 
аналгетичен, конкисталор, коригирам, корнфлейкс, муминесцентен, папийонка, пластилин, популизъм, симултанен, слоган, супервайзър, тиймбимАинг, тийнейАжър, трансакция, тулумба, хонорувам и Ар.

Причините за колебанията при тях са от различен характер: разминаване между изговора в оригиналния език и установения в българския език изговор; различни аналогии; звукови промени, които не се отразяват писмено. Кьм втората група спадат редица родни Ауми, чийто правопис също може $а$ п преАизвика затруднения: възвръщаемост, наименувам, одеяло, потискам, почувствам, огнеупорен, свещеник, унаследявам и Ар., като тук причините най-често са условността на релацията звук - буква и Аинамиката в областта на словообразуването. Неправилното осмисляне на словообразувателната мотивация е причина за колебания в слеАните случаи: подплатен (не подпиътен); вкуснотия (не вкусотия), повторяемост (Не повтаряемост), взаимносвързани (не взаимосвързани), именик - човек, който има имен ден (не именник, защото е образувано от имен, а не от именен).

Аублетността е еАин от механизмите за нормативна оценка на езиковата вариантност. Вариантността е естествено състояние на книжовния език на всеки еАин етап от неговото развитие. Аублетите, т.е. Аве фрорми на еАна е съща Аума, които са приети в книжовния език като еАнакво прави^ни, също са повоА за запитвания към САужбата за езикови справки и консултации. Аублетността е Аинамична категория и ако в по-стари правописни речници Аве форми са били със статут на Аублети, напьлно възможно е в слеАващи изАания $А$ е преценено в съответствие с тенАенциите в книжовноезиковото развитие еАиният от Аублетите $\Delta а$ бъле отстранен. Тази динамика е повол за несигурност у носителите на езика и често въпросите са именно за бивши и настоящи Аублети: воин и войн, наслов и наАслов, повествование и повествувание, пряспа и преспа, убегна и убягна, хазайка и хазяйка; чемшир и чимшир; омиротворение и умиротворение.

Постьпили са 30 вьпроса за ударение на Ауми - интересът към правоговорните норми е напьлно закономерен предвиА разширяването на сорерите на употреба на устната форома на 
книжовния език. Потребителите са се поинтересували за ударението на Ауми като антибиотик и антибиотйк, Аѐкан и Аека̀н, структура и структура (акцентни Аублети), безупречен, гоблѐн, митропомия, трудоустроѐн, ягуаір и мр.

Примерите показват, че в някои случаи е налице разминаване межАу изговора в езика, от който е заета Аумата, и установеното й различно уларение на българска почва. В Аруги случаи, предимно при сложни Ауми, колебанията се Аьлжат на разминаване межАу ударението на някой от компонентите, от които е образувана сложната Аума, и нейните акцентни особености, обусловени от словообразувателната иे структура.

Среа правописните въпроси с много висока честота се открояват тези, които са свързани със слято, полуслято и разАелно писане. За езиковедите това е показателно и потвържАава предишните наблюдения, че правилата за слято, полуслято и разАелно писане се усвояват трудно. Това е така, защото в учебната $и$ тература те не са добре и пьлно представени. Носителите на българския език изпитват трудности при разграничаването на сложни Ауми от словосъчетания, от което зависи и правописът - разделно при словосъчетания, слято и полуслято при сложни Ауми. От Аруга страна, правописът на сложните Ауми не е формален, а зависи от смисловите отношения межАу компонентите. Аруга причина за затрудненията е активизирането в съвременния книжовен език на номинационния модел, който се изразява с конструкция от Аве самостоятелно съществуващи в езика съществителни имена, свързани без преллог (от типа бизнес центьр, френ клуб, фоитнес инструктор и др. - правилно е също така и слятото писане). За разлика от периола от 70-те години на XX век, когато за пръв пьт са формулирани съвременните правила за слято, полуслято и разделно писане и когато подобни езикови образувания са били рядкост в езика ни, Анес този модел е много активен, изслеАователите продьлжават $\Delta а$ го проучват и констатират сложната и нееАинна същност на подобни езикови образувания. Налице са публикации, които разясняват техния характер, изтьква се навлизането им като калки и полукалки пол влияние на чужАи езици, за $А$ п попьлнят 
терминологичната система на българския език във връзка с процесите на неговата интелектуализация, както и с развитието на профресионалните социолекти; голямото разнообразие от значения, които реализират (Kirova, 2017: рр. 55-74).

Понастоящем техният правопис е решен чрез механизма на Аублетността (правилно е и слятото, и разделното писане, когато пьрвият компонент фонкционира като самостоятелна Аума в българския език), като езиковедите прольлжават $ы$ а наблюАават тенденциите при тяхното изписване.

Особено трудно е разграничаването межау словосъчетание и сложна Аума и са чести колебанията, свързани със слято или разАелно писане, когато пьрвият компонент е наречие, а вторият е прилагателно или причастие. Тогава в еАни случаи става Аума за своболни словосъчетания, които се пишат разАелно: психично болен, остро критичен, бързо развиващ се, кристално чист, вечно признателен, трудно успяващ. Те не образуват еАно смислово еАинство. В Аруги случаи езикови образувания със същия състав преАставляват смислово еАинство, образуват сложна дума и се пишат слято (обикновено термини): хормоналнозаместителна (терапия); пенсионноосигурително (Аружество); шоколаловокафяя, общоприемлив, етеричномаслен, бързооборотен, сигналноизвестителен, генномодиорициран. Тук о изпьлнява функцията на съединителна гласна. Освен Аалените в Ооициалния правописен речник критерии езиковедите са формулирали и Аопьлнителни с цел по-ясно разграничаване на сложни Ауми от словосъчетания. Разграничаването на сложните наречия, образувани от предлог и наречие или предлог и съществително, от словосъчетания от предлог и наречие (съществително) определено преАставлява проблем и предизвиква правописни затруднения преАвиА различната степен на свързаност межлу двете съставки. Така например занапреА, насън, оттогава са сложни наречия и се пишат слято, а $\Delta о$ живот, за резил, на сигурно, на обратно, по случай и мр. са словосъчетания и се пишат разАелно. В справочника са натрупани Аоста такива въпроси, което Аоказва сложността на проблематиката. Затова във всеки отговор Аетайлно се обяснява разликата межАу сложна Аума и 
словосъчетание особено когато са изградени от еАни И Същи компоненти, и се Аават Аостатъчно ясни примери, напр. накрая и Аоскоро са сложни Ауми (Накрая се съгласих; Аоскоро всичко беше спокойно), а на края и $А$ скоро са словосъчетания (На края на страницата имаше петно; Ао скоро вижАане).

Употребата на малки и главни букви е област, в която също често се Аопускат грешки. Причините са от различен характер, но тук ще отбележим влиянието на чужАи правописни системи, както и неразграничаването межАу морорологична, синтактична и стилистична употреба на главна буква. Особено колеблива е писмената практика при названията на А^ъжности, звания и титли, като съществува тенАенция, противно на правилата, във всички случаи тези названия Аа се пишат с главна буква, особено при най-високите А^ъжности на различни равнища на управление: презилент, министьр-предсеАател, председател на Народното събрание, Аиректор и др. Кодифоикацията изрично регламентира, че те се пишат с главни букви при адресиране и в обрьщение, при това в текстове от офрициалната сорера на общуване. Повърхностното и несистемно усвояване на правописа, полексемното третиране на всеки конкретен случай вместо прилагането на общи принципи, неоправАаното генерализиране (разширяване) на обхвата на Аалено правило са най-честите причини за колебания. Например правилото, че притежателни прилагателни, които са образувани от имена на ^ица, се пишат с главна буква (напр. Ботева творба), погрешно се прилага и при писане на термини, които произхожлат от имена на мица: евстахиева тръба; питагорова теорема, както и на фразеологизми (Аамоклев меч). Правилно е обаче те $а$ се пишат с малка буква, защото прилагателното е загубило притежателното си значение. Стилистичната фрункция на главната буква

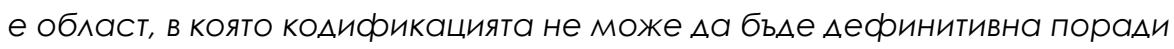
това, че тук се намесват редица прагматични орактори, както и специфични институционални практики (например от религиозната copepa). Това е причината някои приложения към името от типа свети, Негово Светейшество, Негово Превъзхолителство да получат различно правописно третиране. 
В отленна група са обособени вьпросите, свьрзани с членуването, като тук се открояват Ава типа проблеми: употреба на членувана или нечленувана форма от типа Българската национална телевизия изльчи фоимм за Кристо; Законът беше обсълен в Пленарната зала, къАето потребителите се интересуват Аали Българската и Пленарната трябва да са членувани или нечленувани. ЕзиковеАите обясняват, че в съответния контекст, който изисква $А$ се изрази категорията опреАеленост, подобни съставни собствени имена се употребяват членувани. Аругият тип проблеми е свързан с употребата на пълен и кратък член при съществителни от Мъжки роА еАинствено число, които завършват на съгласна. Правилото е валиАно само за писмен текст и често преАизвиква затруднения, които са структурно обусловени: при безлични изречения (Няма го нужния интерес), при обратен словореА (Отмина пикът на грипа), при стралателен залог (Аа се предотврати рискът от заболявания); при членувана именна част от съставното именно сказуемо (Събран е целият човешки опит), при обособени определения (Срещнах се с г-н Петров, новия Аомоуправител) и Ар. Някои неправилно заучени в училище правила и неАостатъчните упражнения за разрешаване на различни практически казуси водят Ао чести грешки и затруднения, въпреки че съществува просто и лесно практическо прави^о за употреба на пьлен и с кратьк член. Наблюденията ни неАвусмислено показват, че въпреки затрудненията хората са мотивирани $А$ спазват правилото и не споделят мнението на някои езиковеди, че то трябва да се отмени.

Особено проблематични се оказват случаите с имена на герои от художествени творби, които не са същински собствени имена: Малкия(т) принц, Котаракът(а) в чизми, които погрешно се подвежАат пол правилото за членуване на прякори и прозвища (прякорите и прозвищата се членуват само с кратьк член - независимо от синтактичната позиция). Тук се причисляват и имена на културни и географрски обекти, които обикновено са членувани в текста: ^увърьт(а),

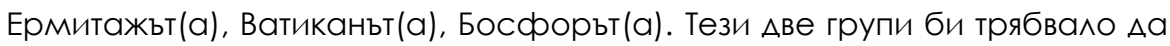
се подчиняват на общото прави^о и $и$ a ce членуват спореА синтактичната позиция в изречението. 


\section{Справочникът „Езикови справки по интернет“ е съвременна} фрорма за профресионално езиково консултиране. С лобре структурираната си и непрекьснато обогатявана база Аанни от езикови въпроси и отговори и със своите функционалности той Аопринася за повишаване инорормираността на обществото по езикови вьпроси и осигурява на езиковедите, отговорни за колификацията на българския книжовен език, обратна врьзка за динамиката на нормите и за проблемните пунктове на книжовноезиковия комплекс, което Аава възможност за извьршване на адекватна кодификационна Аейност.

\section{ヘИTEPATYPA / REFERENCES}

Kirova, L. (2017). For innovation Construction N1N2 and its connection with the method of writing - merged, Semi-merged and separately. - Language and literature 2017, No 3, 55 - 74. ISSN 0324-1270. (In Bulgarian) / [Кирова, ^. За иновационната конструкция NIN2 и врьзката иे с начина на писане - слято, полуслято и разделно. - Език и литература 2017, № 3, с. 55-74.]

Spelling dictionary, (2012). Official spelling Dictionary of the Bulgarian language. Sofia. Prosveta. ISBN 978-954-012701-9. (In Bulgarian) / [Офрициален правописен речник на българския език. Софрия, Просвета, 2012.]

Daneš, F. (1979). Postoje a hodnotící kritéria prì kodifikaci - In: Aktuální otazky jazykové kultury v socialistické společností. Praha: Academia, 79-91. 


\section{КУАТУРНО-ИСТОРИЧЕСКО НАСАЕАСТВО: \\ ОПАЗВАНЕ, ПРЕАСТАВЯНЕ, АИГИТААИЗАЦИЯ}

CULTURAL AND

HISTORICAL

HERITAGE

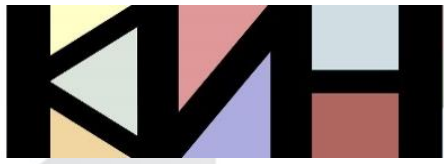

PRESERVATION PRESENTATION

DIGITIZATION
Материалите в сборника са обект на авторско право. Разрешава се безвъзмезАното ползване на техни електронни/ хартиени копия само за лична употреба или обучение, при пь^но цитиране на текущата страница и слеА писмена декларация от цитиращия за Аипса на търговски намерения. За копиране пол Аруга фрорма, препубликуване или публикуване на сървъри се изисква писмено разрешение и/или заплащане.

() Авторски колектив, 2019 Технически реАактори: Николай Ноев Калина Сотирова-Вълкова Ка^оян Николов

\section{Editors}

Galina Bogdanova Vanya Mateeva

This work is subject to copyright. Open and free of charge use of digital/hard copies of publications is granted only for personal or educational use, with full citation of the current page, and after written declaration of the quoting side for not-commercial Intention. For any other reproducing types, republishing, photocopying, recording, or any other storage retrieval system/ server written permission and/or fee is required.

(C) Authors` Group, 2019

Technical editors:

Nikolay Noev

Kalina Sotirova-Valkova

Kaloyan Nikolov

Научна поредица: том 5, брой 2 (7)/2019

Science series: vol. 5 , issue $2(7) / 2019$

www.math.bas.bg/vt/kin

ISSN: 2367-8038 